\title{
INFLUENCE OF VARIOUS DONOR-RELATED FACTORS ON ULTIMATE GRAFT SURVIVAL FOLLOWING PENETRATING KERATOPLASTY
}

\author{
Smita Pawar ${ }^{1}$
}

${ }_{1}^{1}$ Assistant Professor, Department of Ophthalmology, MIMER Medical College, Talegaon-Dabhade, Pune.

ABSTRACT

\section{BACKGROUND}

This prospective study was undertaken to evaluate various donor factors affecting the corneal graft survival to stress on maximum and best utilisation of donor material without compromising the graft outcome.

The aim of this article is to study and correlate effects of corneal morbidity status of deceased and its effect on donor corneas, correlation between time of death and enucleation in relation to time of day, season of the year and influence of various environmental and climatic factors on donor cornea.

\section{MATERIALS AND METHODS}

All surgeries were performed by single experienced anterior segment surgeon. Donor age, cause of death, duration of illness, time of death and time interval between death to enucleation (preservation) time were recorded. Time of the day (morning, afternoon and night) and Season of the year (summer, winter, rainy) along with Place of death (at home/ hospital/ road traffic accident) of donor was studied in relation to corneal graft survival. Only uncomplicated cases of corneal opacity and pseudophakic bullous keratopathy for penetrating keratoplasty were included in the study group.

Statistical Analysis- Chi-square test of significance was applied.

Setting and Study Design- This is a prospective observational study conducted in a tertiary care hospital in Maharashtra.

\section{RESULT}

In a series of 40 penetrating keratoplasty performed during 24 months' time period, the overall percentage of clear graft was $55.26 \%$ at a mean 24 months followup. The survival of the graft did not differ significantly with donor age, $\left(\mathrm{X}^{2}=3.172, \mathrm{P}=0.204\right)$. However, more number of grafts from males survived as compared to those from females in our study, $\left(X^{2}=9.025, P=.002\right)$. Survival of donor graft was not statistically significant for different death to enucleation time, $\left(\mathrm{X}^{2}=0.5, \mathrm{P}=0.90\right)$. Two patients were lost for followup.

\section{CONCLUSION}

Corneas should not be refused for surgery if they satisfy tissue acceptance criteria for optical purpose when corneas are retrieved from aged donors, procured from hospitals/ refrigerated bodies despite prolonged death to enucleation time.

\section{KEYWORDS}

Corneal Graft Survival, Donor Age, Death to Enucleation Time, Seasonal Factors and Graft.

HOW TO CITE THIS ARTICLE: Pawar S. Influence of various donor-related factors on ultimate graft survival following penetrating keratoplasty. J. Evolution Med. Dent. Sci. 2017;6(92):6556-6560, DOI: 10.14260/jemds/2017/1421

\section{BACKGROUND}

National Programme for Control of Blindness (NPCB) estimates that currently 120,000 corneal blind persons are there in the country and every year 25,000 - 30,000 corneal blind cases are added to this list. ${ }^{1}$ The Andhra Pradesh Eye Disease Study ${ }^{2}$ reported $0.66 \%$ prevalence of corneal blindness in at least one eye in their study population and out of them nearly $95 \%$ were classified as avoidable blindness.

Avoidable causes of corneal blindness in India are primarily childhood trauma, keratitis due to vegetative trauma, aphakic and pseudophakic bullous keratopathy, astigmatism post cataract surgery and traditional eye medicines. Many patients suffering from corneal blindness

'Financial or Other Competing Interest': None.

Submission 08-11-2017, Peer Review 20-11-2017,

Acceptance 23-11-2017, Published 04-12-2017.

Corresponding Author:

Dr. Smita Pawar,

Department of Ophthalmology,

MIMER Medical College,

Talegaon-Dabhade, Pune-410507.

E-mail: smita7pawar@gmail.com

DOI: $10.14260 /$ jemds/2017/1421 can be visually rehabilitated by corneal transplantation. Penetrating keratoplasty is the most effective and most commonly performed organ transplantation carried out for treatable corneal blindness.

Over the years there has been significant improvement in corneal graft survival following keratoplasty, but there is a wide gap between corneal graft survival rates in developed and developing countries. Various donor factors have been studied by researchers, which affect graft outcome like age of donor, time interval between death to enucleation, death to preservation time, cause of donor death, seasonal variations etc. The conditions prevailing in developing countries are climatically and socioeconomically quite different from those in developed countries. Therefore, the recommendations made by western studies may not be applicable in our country owing to tropical climate. ${ }^{3}$

Studies establishing clear-cut guidelines regarding usability and viability of donor human corneas in our country are limited and at the same time supply of donor tissue is also limited. This prospective study was undertaken to evaluate various donor factors affecting the corneal graft survival to stress on maximum and best utilisation of donor material without compromising the graft outcome. 


\section{Aims and Objectives}

- $\quad$ To study and correlate effects of corneal morbidity status of deceased and its effect on donor corneas as well as on subsequent keratoplasty.

- To find out any correlation between time of death and enucleation in relation to-

a. Time of day- morning, afternoon and night.

b. Season of the year- summer, winter, rainy.

- To study and correlate influence of various environmental and climatic factors on donor cornea, which may influence graft status.

a. Death at home/ hospital/ road traffic accident.

b. Factors related to surroundings and enucleation- at home/ ICU/ acute ward/ chronic ward.

\section{MATERIALS AND METHODS}

\section{Study Design and Settings}

This is a prospective observational study conducted in a tertiary care hospital in Maharashtra.

- Hospital Ethics Committee approval was taken for our prospective observational study.

- $\quad$ All the surgeries were performed by single experienced anterior segment surgeon. Statistical analysis- Chisquare test was used to know test of significance.

- Patient selection criterion-

1. A total of 40 cases were included in the study. Cases for study were selected from western parts of Maharashtra as well as those referred from various hospitals who attended the cornea and eye bank clinic at tertiary eye care centre.

2. The patients were from all age groups and both sexes.

3. Only uncomplicated cases of corneal opacity and pseudophakic bullous keratopathy for penetrating keratoplasty were included in study groups.

4. All other cases of corneal opacity due to interstitial keratitis, herpes simplex, corneal ulcers and perforation were excluded.

All donor eyes were procured and processed by the hospital eye bank. Active hospital corneal retrieval program was utilised to procure donation after counselling of relatives of donor. Written consent was obtained from the next of kin prior to enucleation. Detailed medical and surgical history was taken to know the cause of death, duration of illness, critical condition prior to death, time and site (home/ hospital/ roadside) of death. Known HIV, HBsAg positive cases and death from unknown cause viral encephalitis, ocular malignancy, diseased and inflamed eyes with corneal involvement, cases of rabies, leukaemia and disseminated lymphomas were absolute contradiction in procurement of donor tissue.

Enucleation was performed within 6 hours in all cases. Each globe was rinsed with normal saline followed by betadine and ciprofloxacin eye drops. HIV and HBsAg status was determined using blood samples from dead body and subjecting it to serological testing. Storage of enucleated eye was done at eye bank by using moist chamber at 4-degree centigrade or MK medium at 4-degree centigrade. Storage time of graft was recorded in every case. Donor tissue was fully evaluated subjecting it to slit lamp examination. Slit lamp examination consisted of evaluation of epithelial status, oedema, Descemet's folds and corneal thickness. Cornea was graded as Grade A, Grade B +ve, Grade B -ve, Grade C, Grade D. Only Grade A, B +ve and B -ve were used for transplantation. After grading, the corneas were again given antibiotic treatment and transferred to preservative bottles.

An initial scleral incision $2-3 \mathrm{~mm}$ post corneoscleral limbus was given in the enucleated eye followed by excision of corneoscleral rim using corneoscleral scissors. Scleral incision was completed in all 360 degrees. Separation of ciliary body attachments to scleral spur was carried out taking care to prevent collapse of anterior chamber. Every precaution was taken to avoid damage to endothelium.

\section{Written Informed Consent for Surgery was obtained}

a. Preoperative preparation- eyelashes were trimmed. All patients were given oral tablet ciprofloxacin $500 \mathrm{mg} 12$ hours prior to surgery. Ciprofloxacin eye drops were instilled 4 hourly prior to surgery. All patients received $200 \mathrm{~mL} 20$ percent mannitol 2 hours prior to surgery.

b. Surgical technique- Surgery was carried out under peribulbar block for cooperative adults. The donor corneal button was obtained under strict aseptic condition with a disposable trephine. The size of donor button varied from 7 to $8.5 \mathrm{~mm}$ ( $0.5 \mathrm{~mm}$ oversized). The donor button was thoroughly washed and placed in a bowl containing a Viscoelastic substance with its epithelial side down. In case of corneoscleral button, the donor button was obtained by posterior punch method using Teflon block. Grading of cornea was again recorded. The recipient face was painted with betadine and draped under aseptic precaution. Lid speculum was applied and eye was then jet washed with normal saline. Superior and inferior rectus bridle suture were taken to stabilise the globe. Vessels if any extending deep into the opaque cornea was cauterised at the limbus using thermal cautery. Recipient cornea was trephined using a handheld hollow disposable trephine up to $80 \%$ thickness. Anterior chamber was entered with sharp blade. Viscoelastic was injected into anterior chamber to form the AC. Recipient bed was then cut with the help of a pair of curved corneoscleral scissors along the trephined wound. Viscoelastic substance was then injected into the open anterior chamber and donor graft was placed on top. Four initial cardinal fixation 10-0 sutures were given at 12, 6, 3 and 9 o'clock respectively. Continuous 10-0 sutures were placed at the level of Descemet's membrane in the circumference of host-graft junction. Sutures were tightened in the end and the knots tied. Interrupted 10-0 sutures were also used in the majority of cases. At the end of the surgery, patient received $2 \mathrm{mg}$ of dexamethasone and $20 \mathrm{mg}$ of gentamicin subconjunctivally. Pad and bandage was applied after putting Neosporin-H ointment.

c. In the postoperative period, patients were given oral antibiotic and NSAID tablets for 5 days. On the $1^{\text {st }}$ postoperative day pad and bandage was removed, eyes cleaned and examined, topical antibiotic and steroid drops were put and the eye was bandaged again. On the second postoperative day, bandage was removed and eye shade was given. The patients were reviewed daily for few days, weekly for 2 months, bimonthly for six months and then every month for a year. Subsequent followup 
period ranged from 6 months to 1 year. During the followup period patients were assessed for visual acuity, graft clarity, refraction, keratometry readings, IOP, signs of rejection of graft, uveitis, vascularisation, wound integrity and condition of sutures. Cycloplegics, topical $0.1 \%$ Dexamethasone drops were given to all patients from second day onwards and tapered over 6 months. Dexamethasone was substituted with fluorometholone eye drops twice daily. Hypersol, lubricating eye drops and timolol were added as and when indicated. Episodes of rejection were treated with topical and systemic steroids. Sutures were removed between 6 - 12 months postoperatively. Early suture removal was done in cases of loose sutures, infiltration or vascularisation at the site of suture. Continuous sutures were removed 6 months postoperatively in most cases. Cyclosporine was used in topical form in single case for treatment of graft rejection combined with steroid-induced glaucoma.

\section{RESULTS}

This study documents the survival rates in a series of corneal transplants and the influence of donor risk factors on transplant survival in a tertiary eye care centre in the developing world.

Total numbers of keratoplasty were 40 . Out of which 2 cases lost for followup and out of 38 grafts 21 grafts survived during 2-year follow-up period.

\begin{tabular}{|c|c|c|c|c|}
\hline Age Group & Total No. & Survived & Failed & Survival \% \\
\hline Less than 50 & 12 & 10 & 02 & 83.33 \\
\hline 50-64 & 14 & 05 & 08 & 35.71 \\
\hline More than 65 & 14 & 06 & 07 & 42.85 \\
\hline \multicolumn{4}{|c|}{ Table 1. Age } \\
\hline
\end{tabular}

The number of survival did not differ significantly with age $\left(\mathrm{X}^{2}=3.172, \mathrm{P}=0.204\right)$.

The mean age of donor in this study was 55 .

\begin{tabular}{|c|c|c|c|c|}
\hline Sex & Total No. & Survived & Failed & Survival \% \\
\hline Male & 23 & 13 & 10 & 56.52 \\
\hline Female & 17 & 08 & 07 & 47.05 \\
\hline \multicolumn{5}{|c|}{ Table 2. Sex } \\
\hline
\end{tabular}

Survival percentage was 56.52 in males.

$\left(\mathrm{X}^{2}=9.025, \mathrm{P}=.002\right)$ More male grafts survived as compared to females in our study.

Graft survival was as under.

\begin{tabular}{|c|c|c|c|c|}
\hline Cause of Death & Total No. & Survived & Failed & $\begin{array}{c}\text { Survival } \\
\%\end{array}$ \\
\hline $\begin{array}{c}\text { Cerebrovascular } \\
\text { death }\end{array}$ & 14 & 04 & 08 & 28.57 \\
\hline $\begin{array}{c}\text { Ischaemic heart } \\
\text { disease }\end{array}$ & 06 & 04 & 02 & 66.67 \\
\hline Trauma & 04 & 03 & 01 & 75.00 \\
\hline Malignancy & 12 & 06 & 06 & 50.00 \\
\hline $\begin{array}{c}\text { Other chronic } \\
\text { debilitating } \\
\text { diseases: } \\
\text { pneumonia, renal } \\
\text { failure, diabetes }\end{array}$ & 04 & 04 & -- & 100.00 \\
\hline \multicolumn{4}{|c|}{ Table 3. Cause of Death } \\
\hline
\end{tabular}

Graft survival was significantly more in corneas acquired from donors suffering from chronic debilitating diseases as compared to corneas acquired from cardiovascular death, trauma or ischaemic heart diseases. Chi-square test $\left(\mathrm{X}^{2}=8.59\right.$, $\mathrm{P}=.07)$.

This was divided into 3 categories.

\begin{tabular}{|c|c|c|c|c|}
\hline Graft Size & Total & Survived & Failed & Survival \% \\
\hline $\begin{array}{c}\text { Less than 7 } \\
\text { mm }\end{array}$ & - & - & - & - \\
\hline $7-8 \mathrm{~mm}$ & 38 & 21 & 15 & 55.26 \\
\hline $\begin{array}{c}\text { More than 8 } \\
\text { mm }\end{array}$ & 02 & - & 02 & - \\
\hline \multicolumn{5}{|c|}{ Table 4. Trephination Size } \\
\hline
\end{tabular}

Donor size of more than $8 \mathrm{~mm}$ was a risk factor, as only 2 grafts had size more than $8 \mathrm{~mm}$ and both failed, but sample size was too small to derive statistical conclusion.

Duration of illness, period of critical illness and duration of hospitalisation did not affect quality of donor tissues as evidenced by equally good graft clarity and survival rates in deaths due to acute as well as chronic debilitating diseases.

\begin{tabular}{|c|c|c|c|c|}
\hline $\begin{array}{c}\text { Duration } \\
\text { of Illness }\end{array}$ & $\begin{array}{c}\text { Total } \\
\text { Grafts }\end{array}$ & Survived & Failed & Survival \% \\
\hline $\begin{array}{c}\text { Less than } \\
\text { 24 hrs. }\end{array}$ & 06 & 04 & 02 & 66.67 \\
\hline $\begin{array}{c}\text { 24 hrs. to } \\
\text { one week }\end{array}$ & 13 & 06 & 07 & 46.15 \\
\hline $\begin{array}{c}\text { More than } \\
\text { 1 week }\end{array}$ & 21 & 11 & 08 & 52.38 \\
\hline \multicolumn{5}{|c|}{ Table 5. Period of IIIness } \\
\hline
\end{tabular}

Chi-square test $\left(\mathrm{X}^{2}=0.32, \mathrm{P}=0.848\right)$

Duration of illness did not affect graft survival significantly.

\begin{tabular}{|c|c|c|c|c|}
\hline $\begin{array}{c}\text { Death to } \\
\text { Preservation Time }\end{array}$ & Total & Survived & Failed & $\begin{array}{c}\text { Survival } \\
\mathbf{\%}\end{array}$ \\
\hline Less than 4 hrs. & 16 & 09 & 07 & 56.25 \\
\hline 4 to 12 hrs. & 21 & 10 & 09 & 47.615 \\
\hline 12 to 24 hrs. & 01 & 01 & -- & 100.00 \\
\hline More than 24 hrs. & 02 & 01 & 01 & 50.00 \\
\hline Table 6. Death to Preservation Time (Enucleation Time) \\
\hline
\end{tabular}

Chi-square test $\left(\mathrm{x}^{2}=0.5, \mathrm{P}=0.90\right)$

Survival of donor graft was not statistically significant for different death to enucleation time.

\section{Environmental Factors}

\begin{tabular}{|c|c|c|c|c|}
\hline Time of Year & Total & Survived & Failed & Survival \% \\
\hline Rainy season & 06 & 04 & 02 & 66.66 \\
\hline Winter season & 17 & 10 & 07 & 58.82 \\
\hline Summer season & 17 & 07 & 08 & 41.17 \\
\hline \multicolumn{6}{|c|}{ Table 7. Season/Time of the Year } \\
\hline
\end{tabular}

\section{Table 7. Season/Time of the Year}

Chi-square test $\left(\mathrm{X}^{2}=0.77, \mathrm{P}=0.6\right)$. The difference was not statistically significant-

1. 22 grafts, i.e. $55 \%$ of cornea were procured from donors who died at night or early morning. External temperatures during this period usually remain less compared to morning or afternoon. All corneas showed superior grading that was collected during night.

2. Most of the corneas were procured from the hospital, where bodies were transferred to mortuary immediately after death and stored at 4-degree centigrade.

3. Effects of season- rainy, summer and winter also made this variable insignificant as far as this study is 
concerned due to above mentioned reasons. This was evident by the fact after 36 hours in one donor who died during summer season, but the graph remained clear in the recipient during 2 years follow-up period. It was noted that grafts tend to survive better in winter season as compared to summer. However, due to small number of cases and short follow-up period in our study, this needs to be further proven.

4. Postoperative uveitis and graft rejection.

Postoperative uveitis was seen in almost all cases, but usually resolved within 3 - 5 days. A few patients had significant postoperative uveitis accompanied by postoperative hypotony. Overall, 13 cases had severe postoperative uveitis. All cases with endothelial rejections were treated with intensive topical and systemic steroids and the cases with epithelial rejections were treated with topical steroids.

\section{DISCUSSION}

\section{Donor Age}

Our study suggests that donor age does not show any significant influence on graft survival as already been shown in previous studies.

The Cornea Donor Study by Sugar $\mathrm{A}^{4}$ et al showed that donor age is not a factor in survival of most penetrating keratoplasties for endothelial disease. Graft survival depends primarily on the state of the endothelial cell layer. Efficient eye banking protocol and allocation of good quality cornea for transplantation regardless of the donor age is the need in current scenario, where most of the donors belonged to aging population stresses the study by Hofmann N. ${ }^{5}$ Similar inferences have been derived by Gain $\mathrm{P}^{6}$ in his study conducted in France. Saini JS7 is also in agreement with this fact and advised to accept corneal tissue from donors of 70 years of age.

In our study, donor in the age group of $50-64$ and $>65$ years were about $35.71 \%$ and $42.85 \%$ respectively and survival of cornea did not differ significantly with donor age.

\section{Sex}

There has been no difference in the outcome of graft survival in relation to sex of donor. This has been documented in a study by Dandona ${ }^{8}$ et al. In our study, we found male graft survived better as compared to graft from female donors.

\section{Donor Size}

Donor size was not a significant risk factor in multivariate study by Sugar A. ${ }^{4}$ In our study, most of the grafts were of the 7 - 7.5 size. Only 2 grafts were larger than $8 \mathrm{~mm}$ size and both failed.

\section{Cause of Death}

Cornea should not be rejected just on the basis of suspected septicaemia; rather better decontamination strategy for the enucleated eye should be practised as opined by Saini ${ }^{7}$ et al. They found no correlation of primary graft failures to the cause of death. They also found that sterility of anterior chamber was not compromised by chronic debilitating disease or terminal bacteraemia as suggested by graft survival rate. In our study also, we found grafts received from donors suffering from chronic debilitating diseases statistically survived better as compared to grafts from donor died due to cerebrovascular causes, trauma or ischaemic heart diseases.

Kalevar $^{3}$ has observed cornea remains transparent in a greater percentage and for a longer period in cases of sudden death than in deaths after chronic ailments.

\section{Death to Preservation Time (DTPT)}

There are no uniformity in criterion as what should be acceptable limits for DTPT, since climatic conditions differ in different countries and also vary depending upon season. Bock $^{9}$ suggested that corneal excision can be done up to $12 \mathrm{~h}$ after death, provided the cadaver is refrigerated. Paton ${ }^{10}$ permitted $5 \mathrm{~h}$ of time interval provided antibiotic drops is instilled, eyelids are closed and the body is refrigerated. Paufique 11 permitted an interval of $24 \mathrm{~h}$, but if the above conditions cannot be fulfilled he suggested enucleation within $6 \mathrm{~h}$ after death.

Donor corneal study by Sugar J12 recommends DTPT $\leq 12$ $\mathrm{h}$ if donor body is refrigerated or eyes iced and $\leq 8 \mathrm{~h}$ if not. In contrast, most of the studies in tropical countries with hot and humid climate restrict $6 \mathrm{~h}$ as cut-off for unrefrigerated bodies in their eye banks. Like Kalevar has quoted, Bock who had suggested 12 hours of cadaver time if refrigeration of donor body was used. Mohamed $\mathrm{A}^{13}$ has also accepted DTPT 6 $\mathrm{h}$ to $10 \mathrm{~h}$ provided donor cornea meets the criteria of tissue acceptance for optical use. We have also got similar results in our study that showed survival was not affected by different DTPT time provided body was refrigerated.

\section{Place of Death}

Most of the corneas were procured from hospital only where awareness regarding care of eyes after death is high being a tertiary care centre. Dead bodies were shifted to mortuary at the earliest, therefore good quality of corneas were procured. Only 4 corneas procured from outside the hospital (home) were included in the study, which were from young donors. One eye has undergone endophthalmitis and others developed late postoperative infection with subsequent graft failure, possibly due to contamination of donor eyes. One patient lost for follow-up, where cornea was procured from home.

\section{CONCLUSION}

In a series of 40PK performed during 24 months' time period, the overall percentage of clear graft was $55.26 \%$ at a mean 24 months followup. We conclude that-

Corneas should not be refused for surgery if they satisfy tissue acceptance criteria for optical purpose when-

a. Corneas are retrieved from aged donors.

b. Corneas procured from hospitals/ refrigerated bodies despite prolonged death to enucleation time.

More effective sterilisation of external surface of donor eye should be carried out to prevent post keratoplasty infection, especially in cases of corneas procured from outside the hospital.

\section{Limitations}

Small number of cases and short followup period in our prospective study need further confirmation of the results. 


\section{ACKNOWLEDGEMENT}

I am extremely grateful to Dr. Swati Raje, Assistant Professor, Department of Community Medicine for her contribution in statistical analysis for the study.

\section{REFERENCES}

[1] Gupta N, Tandon R, Gupta SK, et al. Burden of corneal blindness in India. Indian J Community Med 2013;38(4):198-206.

[2] Dandona R, Dandona L. Corneal blindness in a southern Indian population: need for health promotion strategies. $\mathrm{Br}$ J Ophthalmol 2003;87(2):133-141.

[3] Kalevar V. Donor cornea for keratoplasty. Tropical factors influencing its usability and viability. $\mathrm{Br}$ J Ophthalmol 1965;49(9):490-6.

[4] Sugar A, Gal RL, Kollman C, et al. Factors associated with corneal graft survival in the cornea donor study. JAMA Ophthalmology 2015;133(3):246-54.

[5] Hofmann N, Derks M, Börgel M, et al. Influence of the donor age on graft survival: Is the demographic change also important for corneal tissue donation? Der Ophthalmologe 2017;114(5):440-4.
[6] Gain P, Rizzi P, Thuret G, et al. Corneal harvesting from donors over 85 years of age: cornea outcome after banking and grafting. J Fr Ophtalmol 2002;25(3):27489.

[7] Saini JS, Reddy MK, Sharma S, et al. Donor corneal tissue evaluation. Indian J Ophthalmol 1996;44(1):313.

[8] Dandona L, Naduvilath T, Janarthanan M, et al. Survival analysis and visual outcome in a large series of corneal transplants in India. British Journal of Ophthalmology 1997;81(9):726-31.

[9] Bock RH. A new instrument for lamellar keratoplasty. Arch Ophthal 1950;44(2):293-9.

[10] Paton RT. Keratoplasty. New York: The Blakiston Division McGraw-Hill Book Co. Inc., 1955.

[11] Paufique L, Sourdille GP, Offret G. The corneal transplants [Lesgreffes de la cornée]. Paris: Masson 1948.

[12] Sugar J, Montoya M, Dontchev M, et al. Donor risk factors for graft failure in the cornea donor study. Cornea 2009;28(9):981-5.

[13] Mohamed A, Chaurasia S, Garg P. Outcome of transplanted donor corneas with more than $6 \mathrm{~h}$ of death-to-preservation time. Indian J Ophthalmol 2016;64(9):635-8. 